\title{
Conventos, monasterios y propiedad urbana en Lima, siglo XIX: el caso de la Buenamuerte
}

\author{
Pablo Luna \\ Université Paris Sorbonne, Paris IV \\ pfluna@yahoo.com
}

Fecha de recepción: 15 de septiembre de 2002

Fecha de aceptación: 1 de octubre de 2002

\section{Resumen}

En este artículo se analiza el proceso de desvinculación y desamortización de la propiedad urbana en Perú durante el siglo XIX, tomando el caso del Convento de la Buenamuerte; una pequeña orden religiosa masculina establecida en la ciudad de Lima desde finales de la Colonia. El autor se propone aproximarse a una serie de problemáticas generales relacionadas con el tema, con el fin de que se convierta en una introducción útil con miras a estudios posteriores, tomando como fuente principal la documentación de la Colección Terán depositada en el Archivo General de la Nación (Lima). El texto aborda, entre otros temas, la lógica de funcionamiento del instrumental jurídico desvinculador y desamortizador de mediano plazo creado por el Estado peruano independiente; el deterioro del patrimonio estatal; la identidad social de sus beneficiarios; la evolución de la propiedad de la Iglesia Católica peruana y de las órdenes religiosas; y la ausencia real de un proceso de desamortización eclesiástica, comparable con los de otras realidades del mundo hispanoamericano.

Palabras clave: CONVENTOS, MONASTERIOS, PROPIEDAD URBANA, IGLESIA CATÓLICA, LIMA, SIGLO XIX.

\begin{abstract}
This article analyzes the processes of expropriation and repossession of urban property in Peru during the $19^{\text {th }}$ century, using as a case study the Convento de la Buenamuerte, a small male religious order established in Lima since the end of the Colonial period. The author approaches a series of general research problems related to the topic in order to make a general introduction that might be useful for future studies. Along with other themes, the text attempts to deal the logic behind the medium term juridical instruments created by the independent Peruvian State for repossessing properties; the deterioration of State owned properties; the social identity of those benefited by the process; the evolution of Peruvian Catholic Church owned properties and those of the religious orders; the absence of a real process of ecclesiastic repossession comparable to that of other Hispanic american realities, etc. All these subjects are analyzed through documents belonging to the Colección Terán held in the Peruvian National Archive (AGN).
\end{abstract}

Key words: CONVENTS, URBAN PROPERTY, PERUVIAN CATHOLIC CHURCH, LIMA, $19^{\mathrm{TH}}$ CENTURY.

Fronteras de la Historia 7 (2002)

(C) ICANH 


\section{Introducción problemática}

El proceso de la desvinculación y desamortización de la propiedad en Perú aún no ha sido examinado con el suficiente detenimiento. Las invocaciones para que se asuma su estudio han sido varias ${ }^{1}$, pero es muy probable que las dificultades documentales y las derivadas de un insuficiente dominio del utillaje conceptual, jurídico y económico puedan explicar este vacío.

Hace falta, por ejemplo, para el siglo XIX, una cronología suficientemente razonada de las diferentes coyunturas sociopolíticas en las que observa una ofensiva liberal contra estas formas antiguas de posesión ${ }^{2}$; no disponemos por el momento de tal herramienta básica de trabajo. No se ha reconstruído todavía, ni la lógica ni el funcionamiento del instrumental jurídico desvinculador y desamortizador de mediano plazo creado por el Estado peruano independiente ${ }^{3}$. Aún no se ha medido con precisión el deterioro del patrimonio estatal y, fuera de intuiciones generalmente justificadas, se desconoce efectivamente la identidad social de sus beneficiarios ${ }^{4}$. Una nebulosa incierta recubre todavía las interrogantes sobre la evolución de la propiedad de la Iglesia Católica peruana y de las órdenes religiosas, y la ausencia real de un proceso de desamortización eclesiástica, comparable con los de otras realidades del mundo hispanoamericano ${ }^{5}$. Muy poco sabemos de la aplicación efectiva de las diferentes medidas

\footnotetext{
- Una versión preliminar de este texto fue presentado como ponencia en el XII Congreso Internacional de la AHILA, Oporto (Portugal), Simposio: "El proceso de transformación del régimen de la propiedad en América española, siglos XVIII y XIX", el 23 de septiembre de 1999. La primera versión de este artículo ha contado con los comentarios y críticas de varios colegas y amigos (Abelardo Levaggi, Jean Piel, Diana Millies y Patricia Fogelman, entre otros) a quienes agradezco por su gentileza y competencia. Queda claro, sin embargo, que los errores y deficiencias que puedan percibirse en esta versión definitiva corren por cuenta exclusiva de su autor.

${ }^{1}$ Citemos, para dos cuestiones específicas, a dos historiadores peruanos: Pablo Macera, "Iglesia y economía en el Perú durante el siglo XVIII", en Trabajos de Historia (Lima: INC, 1977), 2:195 y ss., en relación con la propiedad y economía eclesiásticas; y Jorge Basadre, Historia de la República del Perú (Lima: Ed. Universitaria, 1968-1969), 2:368-372, en relación con el menoscabo de la propiedad pública, desde los inicios de la república y durante todo el siglo XIX.

${ }_{2}^{2}$ Los trabajos de Pilar García Jordán permiten una primera aproximación a esta cuestión de base. Ver en particular Iglesia y poder en el Perú contemporáreo, 1821-1919 (Cusco: Centro Bartolomé de Las Casas, s.d. (1991?), y "Estado moderno, Iglesia y secularización en el Perú contemporáreo (1821-1919)" Revista Andina, no 2, (1988): 351401. Sin embargo, es posible afirmar que la necesidad de una cronología razonada de dicho proceso queda aún por satisfacer.

${ }^{3}$ El intento pionero, esbozado por el abogado liberal Francisco García Calderón, en su Diccionario de la legislación peruana, 2 vols. (Lima, Paris: Librairie de Laroque Jeune, 1879), no ha sido enriquecido, ni prolongado hasta fines del siglo XIX. Fuera de algunas tesis sobre asuntos específicos sostenidas en la Universidad de San Marcos. Ver, por ejemplo, Ismael Acevedo y Criado, La institución del Registro de la propiedad inmueble en el Perú, sus antecedentes legales y formas más urgentes (Lima: UNMSM, 1959), 95-182; Víctor D. Larreátegui Hinffen, La prescripción censítica como doctrina legal (Lima: UNMSM Facultad de Jurisprudencia, Imp. La Industria, 1902).

${ }^{4}$ Jean Piel ha avanzado varias hipótesis sobre la cuestión, desde las primeras páginas de su Capitalisme agraire au Pérou, 2 vols. (Paris: Ed. Anthropos, 1975-1983). Ver también "Las leyes de desamortización y su importancia en el proceso neolatifundista republicano en el Perú, de 1824 a 1924", en Actas del XI Congreso Internacional de AHILA (Liverpool: 1996), 3:257-272.

${ }^{5}$ La problemática queda aún por estudiar de manera precisa, para el conjunto del continente latinoamericano, a pesar de obras y avances de singular importancia; aun cuando la literatura al respecto sea generalmente de valor desigual, espaciada en el tiempo e impregnada de debate político. El grupo de trabajo sobre la transformación del régimen de propiedad de la AHILA (Asociación Europea de Historiadores Latinoamericanistas) contribuye desde hace algunos
} 
estatales sobre redención de censos y capellanías y menos aún de las practicadas localmente, durante los sucesivos y alternativos levantamientos de caudillos locales, en los que frecuentemente, desvinculación rima con ajuste de cuentas y expropiación ${ }^{6}$. No se ha contabilizado verdaderamente el monto de los principales de las "imposiciones" y "fundaciones"que se extinguieron, ni se ha establecido el perfil sociológico de los perdedores.

Nos hemos propuesto en este artículo intentar aproximarnos a estas problemáticas generales, mediante un estudio concreto, relacionado con la Lima urbana del siglo XIX. No podremos responder a cada una de las cuestiones arriba planteadas, pero será una introducción útil, con vistas a estudios ulteriores.

Los trabajos sobre la evolución de la propiedad urbana no son numerosos para el caso peruano ${ }^{7}$. Son más raros aún aquellos que dan cuenta de la participación de la Iglesia Católica y las órdenes religiosas en dicho proceso ${ }^{8}$. El asunto no es baladí. Conocedores de la importancia de las instituciones religiosas en la economía y el régimen de propiedad coloniales, es indiscutible que se trata de un tema clave para entender mejor la transición económica durante las primeras décadas del estado independiente y, más específicamente, la manera en que se diseña o rediseña el paisaje urbano de la capital peruana durante el siglo XIX. Las interrogantes al respecto tampoco faltan.

Está, en primer lugar, el tema del traslado desde el antiguo régimen del conjunto patrimonial en explotación y bajo propiedad de las instituciones católicas, hacia una economía hipotéticamente mercantil, la que tendría que haber desembocado en la formación de un mercado de tierras. Un proceso que hay que situar, desde luego, en el propio contexto de la independencia e implantación de la república. Están luego la negociación y adaptación de la Iglesia Católica a las condiciones sociopolíticas generadas por las primeras décadas republicanas y a la ofensiva

años a reactivar los estudios concretos y el debate general. Ver al respecto la introducción de Rosa María Martínez de Codes, "El proceso desvinculador y desamortizador de bienes eclesiásticos y comunales en la América Española, siglos XVIII y XIX" Cuadernos de Historia Latinoamericana, no. 7 (1999): 7-31. Ver también el espacio web de la AHILA: www.ahila.nl, en donde se puede consultar el programa de trabajo de dicho grupo.

${ }^{6}$ Los datos relativos a estas iniciativas locales aparecen episódicamente en determinadas fuentes. Ver, por ejemplo, García, Diccionario, 1:380-385, quien cita las redenciones obligatorias practicadas por el "gobierno revolucionario" del general Vivanco, en Arequipa, en 1858, y las verificadas en Moquegua, durante la "revolución" de 1868.

${ }^{7}$ Las referencias a esta problemática son relativamente marginales en las obras que tratan sobre la evolución de la capital peruana. Ver, entre otros, Juan Bromley y José Barbagelata, Evolución urbana de la ciudad de Lima (Lima: Tall. Gráf. Ed. Lumen, 1945), 128. Carlos B. Cisneros, "Monografía del Departamento de Lima", Boletín de la Sociedad Geográfica de Lima, (1911) 26:121-181, 27:48-57, 28:181-234, 279-320. José María Córdova y Urrutia, Estadística histórica, geográfica, industrial y comercial de los pueblos que componen las provincias del Departamento de Lima, 2 vols. (Lima: Imprenta de Instrucción Primaria, 1839). Manuel Atanasio Fuentes, Guía del viajero en Lima. Guía histórico-descriptiva, administrativa, judicial y de domicilio de Lima, (Lima: Librería Central, 1860), 317. Aurelio Miró Quesada, "Lima en 1839", Boletín de la Sociedad Geográfica de Lima 82, (1964): 53-59. Aldo Panfichi, "Urbanización temprana en Lima 1535-1900”, en Aldo Panfichi H. y Felipe Portocarrero S., Mundos interiores: Lima 1850-1950 (Lima: CIUP, 1995), 16-42.

${ }^{8}$ Citemos, por ejemplo: Redescubramos Lima: Iglesia de San Pedro (Lima: Fondo Pro-recuperación del Patrimonio Cultural de la Nación, 1996), 61. Benjamín Gento Sanz, OFM, San Francisco de Lima; estudio histórico y artístico de San Francisco (Lima: Imp. Torres Aguirre, 1945), xxxii. 
episódica de las fuerzas liberales, frente a la cual se alzará la resistencia de la jerarquía católica y la de sus aliados sociológicos.

Pero se puede evocar también la variada respuesta de la Iglesia y las órdenes, poseedoras de fincas, casas, tiendas, pulperías y callejones de cuartos, ante el aumento de la demanda urbana limeña, notable en particular en la segunda mitad del siglo XIX, y la ampliación relativa de las operaciones de crédito con garantía hipotecaria. En un proceso en el que se observan al mismo tiempo la apropiación (o reapropiación) de la capital peruana por sectores económicamente emergentes ${ }^{9}$, el no sólo simbólico derrumbe de las murallas que cercaban a Lima, lo que abre las compuertas de la apacible ciudad colonial, y la expansión de la actividad de las compañías urbanizadoras, potenciada por la evolución de los precios de las superficies suceptibles de construcción y expansión ${ }^{10}$.

El disponer de un "tableau général" cualitativo y cuantitativo de la estrategia propietal de las instituciones católicas, fuera de contribuir al conocimiento de las problemáticas inicialmente planteadas, ayudaría incluso a revelar más claramente los componentes del proceso que acabamos de describir.

Como ya lo señalamos, hemos querido acercarnos a nuestro objeto de estudio mediante el examen de un caso concreto. Se trata del Convento de la Buenamuerte (en lo sucesivo cdB) de Lima, también llamado de los padres Crucíferos o de los agonizantes, o padres Camilos. Es una pequeña orden masculina, que no tiene ciertamente la importancia de las grandes y pioneras órdenes de dominicos, franciscanos, jesuitas u otras, también presentes en Lima. Explicaremos no obstante el interés que reviste el revisar la documentación correspondiente a dicha institución eclesiástica.

Sin embargo, antes de proceder a la presentación directa de dicho estudio, sería interesante, en primer lugar, replantear el problema de las fuentes disponibles para un trabajo de esta naturaleza.

\section{Fuentes disponibles, posibilidades}

¿Qué fuentes nos permiten efectuar esta aproximación al proceso desamortizador y desvinculador en Perú, a la evolución del régimen de propiedad durante el "siglo de la transición”, el XIX, y también, al estudio de la presencia y el papel desempeñado por las

\footnotetext{
${ }^{9}$ Ver al respecto, y desde el punto de vista de la nomenclatura callejera, Gabriel Ramón J., "Con la patria en las paredes: la regularización de la nomenclatura urbana de Lima (1861)" Contracorriente, no. 1 (1997): 85-104.

${ }^{10} \mathrm{La}$ ocupación del espacio limeño y las sucesivas apropiaciones del suelo desde su fundación constituyen un asunto que queda aún por estudiar. Luego de esta primera aproximación al tema, a partir de nuestras propias fuentes documentales, nos atreveríamos a afirmar que existen en el sector estudiado de Barrios Altos varias capas propietales y toda una "geología de la propiedad" por reconstituir.
} 
órdenes religiosas en el universo local, barrial, de la Lima urbana? Fuera de la documentación impresa, que no es abundante tal como lo hemos venido sugiriendo, y de los archivos del Vaticano, existen en Lima por lo menos tres tipos de fuentes primarias para desarrollar esta investigación; es lo que hemos intentado utilizar en este estudio preliminar del cdB:

1. Hay, en primer lugar, los archivos propios de los conventos y monasterios. Se sabe que existen; algunas órdenes lo admiten abiertamente ${ }^{11}$, otras no. Sin embargo, su acceso es difícil. Es muchas veces una cuestión de confianza personal de las autoridades actuales de la orden para con el investigador. Para el caso del cdB, el trabajo de Virgilio Grandi, El Convento de la Buenamuerte. 275 años de presencia de los Padres Camilos en Lima ${ }^{12}$, favorable a la obra de la orden, ha utilizado ampliamente la documentación reconstituída, desde la segunda mitad del siglo XIX, por los mismos padres de la comunidad en los locales limeños del cdB. Es una obra de introducción ineludible, si bien ampliamente perfectible. Aunque por el momento lo desconozcamos, es probable que haya trabajos similares relativos a la implantación y el desarrollo de otras órdenes limeñas.

2. Están luego, en segundo lugar, los Archivos Arzobispales de Lima, que contienen una parte de la comunicación establecida entre el Arzobispado de Lima y los propios conventos y monasterios ${ }^{13}$. La documentación es importante, y aunque con muchas lagunas, puede permitir seguir algunos de los procesos de reformulación del régimen de propiedad durante el siglo XIX, en los que intervienen dichos conventos y monasterios. Principalmente gracias a dos tipos de documentos:

a) La elaboración del margesí de conventos y monasterios. Margesí o marguesí, es un "peruanismo" que recubre un conjunto de acepciones: el balance más o menos detallado de las propiedades y las cargas que pesan sobre ellas; el estado de los ingresos y créditos de la orden; la estimación de sus gastos (generalmente sobre una base anual). A pesar de la versatilidad en su periodicidad y forma de elaboración y su carácter incompleto, la reconstitución de dichos elementos y el trabajo cuantitativo efectuado con ellos, han permitido verificar, por ejemplo, para el cdB, la degradación efectiva de su patrimonio urbano durante el siglo XIX, pero han permitido registrar también, en la práctica del cdB, la transición de formas de posesión y usufructo de antiguo régimen (censo enfitéutico, venta a

\footnotetext{
${ }^{11}$ Fue el caso del Convento de la Buenamuerte, durante nuestra entrevista con el padre Guiseppe Villa, responsable limeño actual de la orden, el 11/08/1998, efectuada en los locales del convento, en Barrios altos.

${ }_{12}$ Virgilio M.I. Grandi, El convento de la Buenamuerte. 275 años de presencia de los padres camilos en Lima (Bogotá: Lit. Guzmán Cortés, 1985), 205. Un ejemplar de este trabajo nos fue amablemente comunicado por el padre Villa, el día de nuestra entrevista en Lima.

${ }^{13}$ Archivo Arzobispal de Lima, Guía del Archivo Arzobispal de Lima, 1543-1899. Historia, fondos documentales y reglamento, elaborado por L. Gutiérrez A., J. C. García C., y L. Gómez A. (Lima: Arzobispado de Lima, 1995), 51. Ver también Archivo Arzobispal de Lima, Catálogos, Laura Gutiérrez A., coord. (Madrid: Arzobispado de Lima, Fundación Tavera, AECI, 1999), 1 cd-rom; y Melecio Tineo M., El Archivo histórico arzobispal de Lima y sus fondos documentales (Lima: UNMSM, 1992), $9 \mathrm{f}$.
} 
censo) hacia las formas "modernas" de la locación renovable. Y viceversa. Ya volveremos sobre este asunto en la última parte de este artículo ${ }^{14}$.

b) En segundo lugar, otro tipo de documentos de los archivos arzobispales de utilidad primera es representado por los duplicados de algunos expedientes formados sobre contenciosos y pleitos seguidos por conventos y monasterios (el cdB en nuestro caso) con particulares, sobre diversos motivos de propiedad y posesión, o de réditos y rentas por cobrar. Este tipo de documentación, por su carácter lógico y sintético de recopilación judicial, ya es una aproximación a los mecanismos crediticios y financieros en vigor y al funcionamiento de las fundaciones heredadas del siglo XVIII, muchas de las cuales, como sabemos, subsisten hasta fines del XIX (o más tarde aún), a pesar de la legislación republicana. También volveremos luego sobre este asunto.

3. Luego, en tercer lugar, está el conjunto de fuentes relativas a la propiedad urbana en Lima, depositadas en los Archivos Generales de la Nación: papeles de notarios, documentación de particulares, propiedades del Estado, y, en especial, la documentación de la Colección Terán, la misma que permitió levantar el primer catastro urbano de Lima, a finales del siglo XIX ${ }^{15}$. Gracias a sus extractos de protocolos y escrituras notariales, esta última colección permite reconstituir, también para le caso del $\mathrm{cdB}$, no sólo la historia de los propietarios de una finca, sino también la de las cargas, perpetuas o no, redimibles o no, que se impusieron sobre ellas. Su utilización y adaptación permite observar, por ejemplo, la transformación de antiguos solares limeños, o la de antiguas partes del edifício mismo del convento de la Buenamuerte, en callejones de cuartos; transformación provocada tanto por razones financieras como (probablemente) por el desempeño de la obra de la orden.

Pero volvamos a la peculiaridad de la institución que estamos examinando en este trabajo.

\section{La especificidad de la Buenamuerte}

Aun cuando, como ya lo dijimos, no forme parte de las grandes órdenes religiosas de implantación limeña, la de los padres Camilos se reviste de un conjunto de singularidades que hacen que su estudio sea de utilidad. Por varias razones:

- Desde el punto de vista de su itinerario, es la última orden masculina llegada a Lima, hacia $1709^{16}$. Adquiere paulatinamente importancia, en la segunda mitad del XVIII, incluso como centro intelectual y doctrinario, participando de manera decisiva en las polémicas

\footnotetext{
${ }^{14}$ La reconstitución de la contabilidad del cdB es un asunto arduo cuya ejecución se ve limitada por la carencia de documentos y balances. Sin embargo, cuando la información existe, es posible detectar algunas características que confirman esta valse-hésitation entre "antiguo régimen" y "modernidad".

${ }^{15}$ Archivo General de la Nación, Guía del Archivo Histórico (Lima: AGN, 1997), 43.

${ }^{16}$ El pedido de autorización oficial había sido elevado en 1712, pero sólo fue obtenido en 1736. Grandi, El convento, 20-21
} 
eclesiásticas que se producen en el imperio español o como proveedor de consejo y asistencia espiritual a las autoridades coloniales ${ }^{17}$. Luego, como ocurre con otras órdenes durante el mismo periodo, va a entrar en crisis en la coyuntura del cambio de siglo, decayendo ostensiblemente a lo largo de todo el XIX, para luego "renacer"en el siglo XX y volver a desarrollarse hasta nuestros días ${ }^{18}$.

- Desde el punto de vista de su implantación, la comunidad de la Buenamuerte escoge establecerse en un ambiente popular de la Lima del ochocientos, el llamado Barrios Altos, aglomeración de núcleos poblacionales situados en la periferia de la Lima cuadrada intramuros. Pero la Buenamuerte se implanta tanto al interior como al exterior de las murallas de la Lima colonial, y también lo hace en el barrio "de indios y negros" de San Lázaro, del otro lado del río Rímac ${ }^{19}$, también llamado de Abajo del Puente. Se puede afirmar que junto con otras órdenes limeñas, que optan por zonas de implantación similares, la comunidad de la Buenamuerte es uno de los factores de impulsión y mantenimiento de la religiosidad popular de los barrios limeños marginales ${ }^{20}$.

- Desde el punto de vista de su "misión", la Buenamuerte es específicamente una orden que ayuda a efectuar el tránsito hacia la otra vida, que ayuda a "bien morir", especialmente a los pobres y enfermos a los que asiste y socorre, preferentemente en hospitales y hospicios, aunque también a domicilio o en prisión. Recordemos que se trata de una orden hospitalaria (como la de San Juan de Dios o la de Malta), que fue fundada en 1582 por el futuro San Camilo de Lelis ${ }^{21}$; una orden que se desarrolló al comienzo en Italia, España (Madrid, Barcelona, Valencia, Andalucía), Portugal y Francia, cuya "casa matriz"se situó en Sicilia y que se implantará en América llegando directamente desde Italia. La "casa de Lima", es decir la de Barrios Altos, será la más importante de una implantación que, con diversa fortuna, incluye otras ciudades peruanas, y también Quito, La Paz y en el virreinato de Nueva Granada, la ciudad de Popayán.

Siendo una orden que actúa en un momento crítico y que ayuda a efectuar "el paso de esta vida hacia la otra", es al mismo tiempo un lugar especial para estudiar dos grupos de cuestiones fundamentales, ligadas a nuestras problemáticas iniciales.

\footnotetext{
${ }^{17}$ Ibídem, 29, 51, 84-85. Algunas de las principales personalidades de la orden, en particular en el último tercio del siglo XVIII, fueron catedráticos de la Universidad de San Marcos y tomaron parte activa en la publicación del Mercurio Peruano, órgano eminente del grupo de "ilustrados" limeños.

${ }^{18}$ Signo de los tiempos, la orden de la Buenamuerte ha abierto un espacio internet bilingüe (italiano-inglés), en el que se referencian su obra y sus diferentes lugares actuales de implantación. La dirección web de dicho espacio es http://www.geocities.com/Athens/Agora/2070.

${ }_{19}$ Se trata de la "Casa de Santa Liberata", fundada en honor de la patrona de la ciudad de Sigüenza. Grandi, El Convento, 21-26.

${ }^{20}$ Una marginalidad definida en términos geográficos, respecto al cuadrado central, pero también en términos sociales y raciales.

${ }^{21}$ Sus miembros formulan los votos clásicos (pobreza, castidad y obediencia) además de los de ayudar espiritual y materialmente a los moribundos, en los hospitales, cárceles y a domicilio. La creación de la orden había sido confirmada, en 1591, por el papa Sixto V. Ver, entre otros: Agnès Gerhards, Dictionnaire historique des ordres religieux (París: Fayard, 1998), 122-123. Charles Goutier, «L'ordre de Saint-Camille», en Enciclopedia Universal Espasa Calpe (París, 1926), 3:396. Ch. Poulet, Histoire de l'Eglise (París: Ed. Beauchesne et ses fils, 1953), 2:196. Camilo de Lelis fue santificado en 1746.
} 
Por un lado, las fundaciones de antiguo régimen (aniversarios de misas, buenas memorias, obras y legados píos y capellanías de misas) que crean los agonizantes que pueden hacerlo; aquéllos que, según la fórmula utilizada, "declaran a su alma como heredera de sus bienes", en memoria de quienes es preciso celebrar misas y oficios, aportar "sufragios", de los que depende su salvación eterna. Dichas instituciones imponen a los bienes terrenales una obligación cuyos resultados se obtendrán en el más allá, a favor del fundador; lógicamente, la mayoría de ellas son perpetuas. Los réditos producidos en el siglo por los principales "impuestos" en dichas fundaciones sirven para financiar los oficios y misas elevados a favor del alma del beneficiario ${ }^{22}$.

Por otro lado, esta especificidad de la orden de la Buenamuerte, la de asistencia a los agonizantes en los últimos momentos de su vida, permite reconstituir su estrategia (la de la orden y la de los padres miembros de la comunidad), frente a las donaciones, los legados y testamentos de sus asistidos. Sabiendo la importancia que reviste para los creyentes la presencia de un representante de Dios en el último instante de la existencia, consagrado al arrepentimiento, y tomando en cuenta también la devoción con la que los padres Camilos asumen entonces su misión ${ }^{23}$, la que incluye la búsqueda de recursos para su mantenimiento.

Pero hay otras razones, que se relacionan más con nuestra temática respecto a la propiedad urbana y su evolución durante el siglo XIX, y que hacen interesante que analicemos el desarrollo de la comunidad de la Buenamuerte, desde el momento de su implantación inicial:

1. En primer lugar, como otras órdenes de implantación limeña y peruana, el cdB busca asegurar los medios de su obra mediante la adquisición de propiedades y el aprovisionamiento de fuentes de ingreso seguras y regulares. Quien dice propiedades dice haciendas y fincas urbanas y rurales (y su puesta en explotación); quien dice ingresos dice rentas, censos, capellanías, cánones enfitéuticos, fuera de donaciones puntuales y otros ingresos diversos. Desde este punto de vista, se puede afirmar que existe en el seno de la comunidad y en los capítulos conventuales una estrategia de unidad económica y financiera, acreedora y deudora (censualista y censataria al mismo tiempo), y que al reconstituir dicha estrategia, nos acercamos concretamente a determinados mecanismos de funcionamiento de la economía colonial, reinantes aún en el siglo XIX y que el cdB instrumentaliza en su beneficio. Lo que desde un punto de vista más general, y en ausencia

\footnotetext{
${ }^{22}$ El mecanismo de funcionamiento y la lógica general de dichas fundaciones han sido analizados en diversas ocasiones por Gisela Von Wobeser. Ver en particular "La fundación de capellanías de misas, una costumbre arraigada entre las familias novohispanas. Siglos XVI-XVIII", Jahrbuch für Geschichte Lateinamerikas, no. 35 (1998): 25-44. Y también "Mecanismos crediticios en la Nueva España. El uso del censo consignativo", Estudios Mexicanos 5, no. 1, (1989): 1-23. Ver igualmente los trabajos de Alberto Levaggi, "El proceso desamortizador y desvinculador de los bienes de manos muertas desde la óptica jurídica", Cuadernos de Historia Latinoamericana, no. 7 (1999): 33-60, y su libro Las capellanías en la Argentina, estudio histórico-jurídico (Buenos Aires: UBA, 1992).

${ }^{23}$ En particular durante la segunda mital del siglo XVIII, época floreciente de la obra de la orden. Grandi, El convento, 40, 70, 77, 101. El padre Villa nos habló también, durante nuestra entrevista, de dicha etapa de la evolución de la orden, comparándola con el desafortunado siglo XIX.
} 
de otros medios conocidos, hace que el trabajo monográfico con cada una de estas unidades (conventos, monasterios, beateríos, etc.) sea ineludible en una primera etapa, para reconstituir en detalle su itinerario y el lugar que ocupan en dicho funcionamiento. Es dentro de esta lógica también que se inscribe nuestro interés por el cdB.

2. Pero hay otro conjunto de razones que hacen interesante el seguimiento del cdB. Se trata de un convento pequeño, ya lo dijimos; sus haciendas (las que ha buscado adquirir) están muy cerca de la ciudad de Lima $^{24}$ (el valle de Cañete, Santa Inés, Santa Olalla, Magdalena), producen azúcar, maíz y panllevar, disponen de tiendas de distribución y venta, adjuntas al convento, que atraen a los vecinos. Sin embargo, también resulta interesante observar su estrategia de ocupación y organización del territorio adyacente a su establecimiento urbano inicial. Primero las casas y fincas colindantes, luego la manzana, en seguida casas en otras cuadras,..., aunque sin dejar de ser un foco de vida social local, barrial, en su lugar originario de implantación; con fiestas religiosas públicas regulares (que son singulares lugares de sociabilidad popular de antiguo régimen); con una cohorte de fieles y benefactores locales, cercanos físicamente; con una miriada de mendigos y pordioseros que dependen de la caridad del cdB y de las fundaciones creadas o notarialmente "instituidas" para ellos por particulares. Pero también es interesante el uso de las instalaciones del cdB, lo que se llama su fábrica (que se halla en continuo crecimiento), como un lugar de empleo para numerosos obreros, artesanos y mandaderos de su entorno (en reparaciones y mantenimiento del edificio del cdB o de sus fincas, en servicio doméstico, o como empleados individuales de los padres). Es decir que a la dimension económica y espiritual de su presencia, cabe agregar entonces un componente sociológico en la dinámica de su implantación, en particular en la segunda mitad del siglo XVIII y en la primera del XIX. Así, aproximarse a la vida del cdB es aproximarse también a la sociología de su entorno, a sus relaciones de interdependencia social con los medios populares limeños, con la plebe marginal y marginalizada.

3. Y hay una tercera razón de interés por este convento, ya durante el siglo XIX. Y es que el cdB va a experimentar concretamente el vaivén de la legislación desamortizadora y desvinculadora republicana; un vaivén que, como otros aspectos normativos de la institucionalidad del Perú del siglo XIX, quiere decir frecuentemente aprobación de una ley y su revocación ulterior más o menos inmediata, o su mediatización gracias a un reglamento de aplicación que vacía su contenido ${ }^{25}$, o que suspende temporalmente su vigencia. El cdB será objeto de dos supresiones y dos restablecimientos consecutivos, durante los años 1830 y $1840^{26}$. Como otros conventos y monasterios, el cdB conocerá el despojo y la dilapidación temporal (y a veces definitiva) de una parte de su patrimonio, a favor del Estado peruano o de particulares designados por él, pero igualmente, desarrollará estrategias de resistencia, disimulación y ocultación de propiedades (en las que se sospecha la participación de colaboradores particulares laicos). El cdB asistirá también a la extinción progresiva de las

\footnotetext{
${ }^{24}$ Grandi, Ibídem, 17-18, 28, 37-38, 55, 78.

${ }^{25}$ Para no hablar de las dificultades de aplicación a escala nacional.

${ }^{26}$ Desde agosto de 1829, hasta octubre de 1833; desde agosto de 1843, hasta junio de 1844. Archivo Arzobispal de Lima (en lo sucesivo A.A.L.), Convento de Nuestra Señora de la Buenamuerte (en lo sucesivo CNSB), 9:89, (1830); 10:2, (1833-1840), 10:147, (1843-1846).
} 
fundaciones instituidas en el siglo XVIII y la de los réditos y sus principales correspondientes $^{27}$, en un proceso de desamortización "silenciosa"o "natural". Pero el cdB será igualmente el teatro de la lenta introducción de nuevas formas ("modernas") de valorización de su patrimonio urbano. Al lado de estos procesos, proseguirá también, al interior del cdB, la desagregación de la "vida común" reglamentaria, potenciada por la crisis interna de la orden ${ }^{28}$, al mismo tiempo que experimentará las consecuencias de las políticas de secularización y de primado del individualismo sobre el comunitarismo, también en el campo del usufructo de la propiedad. Se producirá así una curiosa tensión al interior del cdB entre el poseer comunitariamente y el poseer individualmente. Finalmente, conviene recalcarlo, la comunidad de la Buenamuerte es, como otras órdenes, un observatorio local de las relaciones entre Iglesia y Estado, y de la tensión entre "antiguo régimen" y "modernidad", durante el siglo XIX. Es también en ese sentido que nos ha interesado su estudio.

Veamos ahora, luego de estos preámbulos, los resultados obtenidos en nuestro análisis.

\section{Propiedad urbana de la Buenamuerte, durante el siglo XIX}

Hemos efectuado esta aproximación al patrimonio urbano del cdB gracias a la explotación de los datos reunidos en la Colección Terán, que se hallan depositados ${ }^{29}$ en el Archivo General de la Nación. Dicho fondo se constituye de 187 volúmenes encuadernados, compuestos de extractos de protocolos notariales, con sus respectivos índices ${ }^{30}$.

\section{a) Formación de inventario}

\footnotetext{
${ }^{27}$ Conviene señalar que, para este tipo de imposiciones, el término principales se mantiene en las escrituras notariales que hemos revisado, hasta más allá del segundo tercio del siglo XIX, en donde progresivamente deja su lugar a capitales; la propia literatura del periodo manifiesta reticencia para el uso del término capitales. Tal vez no sea una indicación sobre el empleo de vocabulario que convenga pasar por alto.

${ }^{28}$ La crisis de la segunda mitad del siglo XVIII es uno de los grandes problemas de la Ecclesia ibérica. Sus repercusiones en Lima son evidentes, en donde por otra parte se "adapta" y cobra formas específicas.

${ }^{29}$ Para una descripción de la Colección Terán, ver también “Archivo Terán”, Revista del Archivo Nacional del Perú 17, no. 2 (1944): 166-179.

${ }^{30}$ Los documentos de esta colección pertenecían al notario Federico Terán. Fueron comprados por el Estado peruano, el 16 de mayo de 1944 y confiados al Archivo General de la Nación. Dichos extractos de protocolos conciernen operaciones efectuadas con propiedades urbanas y rurales en Lima y sus alrededores, entre finales del siglo XVII y finales del siglo XIX. En su momento, en 1898, permitieron levantar el primer catastro de Lima. Fuera de los extractos de protocolos, clasificados por notarios, existen volúmenes sobre bienes nacionales, sobre las propiedades de la Sociedad de Beneficencia Pública de Lima, al lado de fondos de testamentos y documentos sobre las propiedades de los conventos de Santo Domingo y La Merced. La colección se compone además de 82 cuadernillos suplementarios que contienen también extractos de protocolos. No se sabe aún a ciencia cierta si su contenido ha sido efectivamente vertido a los volúmenes encuadernados.
} 
Gracias al examen de dicha documentación, reunida hasta 1898, año en que concluye el recuento efectuado por la Colección, hemos repertoriado un total de 36 emplazamientos, limeños y urbanos, relacionados por Federico Terán y colaboradores con el cdB. De ellos, 25 aparecen como posesiones efectivas de la comunidad ${ }^{31}$. Se trata generalmente de lugares de habitación, incluso callejones de cuartos $^{32}$, aun cuando haya igualmente tiendas y corralones. La mayoría de dichos emplazamientos se sitúa en el entorno próximo del convento, tal como lo señaláramos anteriormente. De la misma manera, hay que saber que la mayoría de las propiedades urbanas del $\mathrm{cdB}$, tal como se desprende de dicha documentación, han sido objeto de imposiciones y fundaciones diversas, cuyo origen remonta en su mayoría a mediados o a la segunda parte del siglo XVIII. La lista de las propiedades inventariadas es la siguiente:

Tabla No. 1. Lista de emplazamientos del cdB

\begin{tabular}{|c|c|}
\hline Ubicación de la propiedad $^{*}$ & Referencias en la Colección Terán $^{* *}$ \\
\hline $\begin{array}{l}\text { 1) } 90 \text {, Portada del Martinete (Amazonas } \\
\left.6^{\mathrm{a}}\right)\end{array}$ & $\begin{array}{l}363 \mathrm{~B}, 417 \mathrm{v} \text { A, 446v C, 242v J, } 57 \text { T, 250v J, 525v A, } 162 \\
\text { E, 647v L }\end{array}$ \\
\hline $\begin{array}{l}\text { 2) } 257-259 \text {, Calle Mercedarias (Ancash } \\
\left.10^{\mathrm{a}}\right)\end{array}$ & $481 \mathrm{~F}, 480 \mathrm{v} \mathrm{f}, 148 \mathrm{H}$ \\
\hline 3) 202-206, Calle Trinitarias (Ancash 7a) & $480 \mathrm{v} \mathrm{L}, 378 \mathrm{I}, 198 \mathrm{v} N, 235 \mathrm{v} \tilde{\mathrm{N}}$ \\
\hline $\begin{array}{l}\text { 4) } 73,177 \text {, Calle Buenamuerte (Ancash } \\
\left.8^{\mathrm{a}} 1\right)\end{array}$ & $\begin{array}{l}208 \mathrm{~B}, 453 \mathrm{v} \text { F, 80v N, 111v D, } 276 \mathrm{H}, 664 \mathrm{~L}, 12 \mathrm{v} \text { W2, } \\
47 \mathrm{v} \text { W2 }\end{array}$ \\
\hline 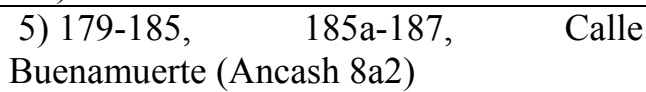 & $208 \mathrm{~B}, 112 \mathrm{E}, 443 \mathrm{M}, 199 \mathrm{v}$ N2 \\
\hline 6) 258, Calle Santa Clara (Ancash 9a) & $57 \mathrm{~T}, 301 \mathrm{M}, 199 \mathrm{~N} 2$ \\
\hline $\begin{array}{l}\text { 7) 28-42, Calle del General (Andahuaylas } \\
2^{\mathrm{a}} \text { ) }\end{array}$ & $418 \mathrm{~J}, 24 \mathrm{v}$ V2, 80v V2 \\
\hline 8) 176-184, Calle Bravo (Arica 7a) & 46 G, 328v S, 21v Ñ, 225 W \\
\hline $\begin{array}{l}\text { 9) } 29-45 \text {, Calle Santa Liberata (Atahualpa } \\
\left.1^{\mathrm{a}}\right)\end{array}$ & $100 \mathrm{~N}, 357 \mathrm{v}$ I, $107 \mathrm{~W}, 137 \mathrm{~W}, 148 \mathrm{v} \mathrm{W}$ \\
\hline
\end{tabular}

\footnotetext{
${ }^{31}$ Siete emplazamientos registran operaciones en las que participa, de una u otra forma, la comunidad, sin tener por el momento la certeza de que sean poseídos por el cdB. Hay finalmente cuatro emplazamientos adicionales sobre los que no disponemos aún de información que justifique la relación que Terán establece con el cdB. Ver tabla no 1.

${ }^{32}$ El origen limeño de los callejones de cuartos queda aún por reconstituir de manera precisa, lo que permitiría alumbrar un sector de la historia de la Lima popular de los barrios coloniales. En este trabajo hemos podido detectar la transformación, a inicios del siglo XVIII, de antiguos solares en callejones, ocasionada por la dificultad y la insolvencia de determinadas familias para hacer frente a obligaciones contraídas. Ver, por ejemplo: Archivo General de la Nación (A.G.N.), Colección Terán (CT). Casa no 111-115, calle Ranchería de los Patos o Pampilla de los Leones, 30v C (20/03/1767), 386 A (09/10/1781), 11 R (08/08/1783).

*El primero es el nombre antiguo de la calle; entre paréntesis hemos inscrito su nombre actual, que es el que utilizaremos en nuestras referencias ulteriores, y la cuadra en la que se sitúa el emplazamiento considerado.

${ }^{* *}$ Se trata, en cada caso, del número del folio y de la letra de clasificación del volumen de referencia.
} 


\begin{tabular}{|c|c|}
\hline $\begin{array}{l}\text { 10) 130-140, Calle de la Acequia } \\
\text { (Caylloma 5a) }\end{array}$ & $10 \mathrm{v} \mathrm{H}, 10 \mathrm{H}$ \\
\hline 11) $1-5$, Calle Rufas (Huanta $\left.1^{a} 1\right)$ & $417 \mathrm{v}$ A, $525 \mathrm{v}$ A, $14 \mathrm{v} \tilde{\mathrm{N}}$ \\
\hline 12) 43, Calle Rufas (Huanta 1a2) & 346v G, 158v N \\
\hline $\begin{array}{l}\text { 13) 22-22c, 24-34, 36-42, Calle Rufas } \\
\text { (Huanta 1aCouv1) }\end{array}$ & $\begin{array}{l}65 \mathrm{~F}, 353 \mathrm{v} \mathrm{M}, 372 \mathrm{M}, 331 \mathrm{v} \mathrm{S}, 415 \mathrm{v} \mathrm{G}, 433 \mathrm{v} \mathrm{J}, 445 \mathrm{~J}, 101 \\
\tilde{\mathrm{N}},\end{array}$ \\
\hline 14) 46, Calle Rufas (Huanta $1^{\mathrm{a} C o u v 2)}$ & $22 \mathrm{~T}, 61 \mathrm{~T}, 199 \mathrm{~N} 2,285 \mathrm{v} \tilde{\mathrm{N}}$ \\
\hline $\begin{array}{l}\text { 15) } 99-103,113 \text {, Calle de las Cruces } \\
\text { (Huanta 2a) }\end{array}$ & $\begin{array}{l}57 v \text { B, } 376 \text { G, 446v S, 189v H, 372v J, } 377 \text { J, 402v J, 82v } \\
\text { W, 436v J }\end{array}$ \\
\hline 16) 112, Calle Pejerrey (Jauja $\left.2^{a}\right)$ & n. d. \\
\hline $\begin{array}{l}\text { 17) 52-54, Calle Mariquitas (Moquegua } \\
3^{\text {a) }}\end{array}$ & $162 \mathrm{E}, 648 \mathrm{~L}, 287 \mathrm{H}$ \\
\hline 18) 49-53, Calle Quemado (Moquegua 4a) & $223 \mathrm{~B}, 89 \mathrm{E}, 162 \mathrm{E}, 231 \mathrm{~W}$ \\
\hline 19) 32, Calle Penitencia (Paruro 1a3) & $53 \mathrm{~T}, 648 \mathrm{~L}$ \\
\hline $\begin{array}{l}\text { 20) } 3,9,41,45 \text {, Calle Penitencia (Paruro } \\
1^{\mathrm{a} 4} \text { ) }\end{array}$ & $655 \mathrm{~L}$ \\
\hline 21) 7, Calle Penitencia (Paruro 1a5) & $328 \tilde{\mathrm{N}}$ \\
\hline 22) 27-29, Calle Penitencia (Paruro 1a6) & $\begin{array}{l}\text { 77v C, } 132 v \text { G, } 133 \text { G, } 392 \text { L, } 363 \text { M, } 319 \text { I, } 649 \text { L, 434v } \\
\text { I, 469v J, 592v I, }\end{array}$ \\
\hline 23) 31-35a, Calle Penitencia (Paruro 1a7) & $139 \mathrm{~S}, 275 \mathrm{v} \mathrm{H}, 662 \mathrm{I}$ \\
\hline 24) 37-47, Calle Penitencia (Paruro 1a8) & 77v C, 390v F, 484 L, 335v N \\
\hline 25) 99-103, Calle Pajuelo (Paruro $3^{\mathrm{a}}$ ) & n. d. \\
\hline \multicolumn{2}{|l|}{ Propiedad del cdB sin confirmar } \\
\hline 1) 388, Calle San Salvador (Ancash 11a) & $480 \mathrm{v} \mathrm{F}, 193 \mathrm{H}, 176 \mathrm{v} \mathrm{W}$ \\
\hline $\begin{array}{l}\text { 2) 111-115, Calle Ranchería de los patos } \\
\text { o Pampilla de los leones (Arequipa } 6 a \text { ) }\end{array}$ & $\begin{array}{l}30 \mathrm{v} \text { C, } 386 \mathrm{~A}, 11 \mathrm{R}, 376 \mathrm{v} \mathrm{C}, 118 \mathrm{I}, 119 \mathrm{I}, 564 \mathrm{~L}, 168 \mathrm{v} \text { N, } \\
169 \mathrm{v} \mathrm{N}, 174 \mathrm{~N}, 176 \mathrm{~N}, 173 \mathrm{v} \text { N, 37v V2 }\end{array}$ \\
\hline $\begin{array}{l}\text { 3) } 4 \text { (6 ?), Calle los Sauces de Santa Clara } \\
\text { (Jauja 1a) }\end{array}$ & $362 \mathrm{~B}, 405 \mathrm{~A}, 109 \mathrm{v} N, 242 \mathrm{~S}, 798 \mathrm{v}$ A, 355v J \\
\hline 4) 181, Calle Zárate (Junín 4a) & $\begin{array}{l}42 \mathrm{v} \mathrm{J}, 134 \mathrm{v} \mathrm{F}, 288 \mathrm{C}, 66 \mathrm{~L}, 163 \mathrm{G}, 70 \mathrm{~S}, 345 \mathrm{~T}, 183 \mathrm{v} \mathrm{W}, \\
\text { 7v W2, } 17 \mathrm{~W} 2\end{array}$ \\
\hline 5) 76-79, Calle Huevo (Tacna 5a2) & $42 \mathrm{C}, 38 \mathrm{C}, 337 \mathrm{v} \mathrm{C}, 112 \mathrm{v} \mathrm{M}, 18 \mathrm{v} \mathrm{S}, 269 \mathrm{v} \mathrm{M}, 247 \mathrm{v} \mathrm{H}$ \\
\hline 6) 94-98, Calle Huevo (Tacna 5a3) & $284 \mathrm{vU}, 196 \mathrm{I}, 715 \mathrm{~A}, 272 \mathrm{v} \mathrm{S}$ \\
\hline 7) 164-164b, Calle Capón (Ucayali 7a) & $\begin{array}{l}44 \mathrm{P}, 221 \mathrm{v} \mathrm{S}, 48 \mathrm{v} \mathrm{Q}, 307 \mathrm{M}, 241 \mathrm{v} \mathrm{S}, 103 \mathrm{v} \mathrm{W}, 134 \mathrm{~W}, \\
153 \mathrm{v} \mathrm{W}, 441 \mathrm{~J}, 456 \mathrm{~J}, 168 \mathrm{v} \mathrm{W}, 216 \mathrm{~W}, 225 \mathrm{~W}, 272 \mathrm{~W}, \\
304 \mathrm{~W}, 310 \mathrm{~W}, 35 \mathrm{v} \text { V2, } 14 \mathrm{H} 2\end{array}$ \\
\hline \multicolumn{2}{|l|}{$\begin{array}{c}\text { Sin conexion con el cdB, incluídas por } \\
\text { Terán }\end{array}$} \\
\hline 1) 146-156, Calle Zamudio (Cuzco 6a) & $80 \mathrm{v}$ V2, 372v M, $308 \mathrm{I}, 317 \mathrm{I}, 433 \mathrm{v}$ I, 544v L, 558v L \\
\hline 2) 2-4m, Calle Penitencia (Paruro 1a1) & $225 \mathrm{v} F, 399 \mathrm{~B}, 60 \mathrm{~T}, 21 \mathrm{E}, 21 \mathrm{v} \mathrm{E}, 429 \mathrm{v} \mathrm{I}, 430 \mathrm{v} \mathrm{I}, 5 \mathrm{H} 2$ \\
\hline 3) 6-8, Calle Penitencia (Paruro 1a2) & $238 \mathrm{C}, 223 \mathrm{~W}, 286 \mathrm{~W}$ \\
\hline 4) 74-74a, Calle Huevo (Tacna 5a1) & $44 \mathrm{v}$ C, $3 \mathrm{C}, 118 \mathrm{I}, 550 \mathrm{v} \mathrm{I}, 562 \mathrm{v} \mathrm{I}$ \\
\hline Total: $\mathbf{3 6}$ emplazamientos & \\
\hline
\end{tabular}


El deterioro del patrimonio urbano de la Buenamuerte parece evidente, si comparamos este primer resultado con estimaciones efectuadas para épocas anteriores. El trabajo de V. Grandi evoca el "gran número de fincas" poseídas por el cdB, antes del establecimiento de la república $^{33}: 23$ casas, 9 tiendas, 1 pulpería, 3 callejones (con más de 460 alquileres mensuales). Gracias a otras fuentes ${ }^{34}$, hemos podido estimar en alrededor de 50 el número de propiedades urbanas poseídas por la comunidad, luego de su primer restablecimiento, en 1834: 8 casas, 25 casitas, 2 callejones de cuartos, 12 tiendas y 2 pulperías.

\section{b) Metodología y límites del enfoque}

Para volver con la documentación de la Colección Terán, y comprender mejor el cuadro de síntesis presentado, cabe precisar la metodología que hemos seguido para establecer tal inventario de posesiones del $\mathrm{cdB}$. Hemos trabajado de la siguiente manera:

- En primer lugar, hemos detectado en los índices de la Colección, los volúmenes n 44-47, todas la referencias de sitios urbanos relacionados con la Buenamuerte. Su resultado concreto es la primera columna del cuadro anterior, es decir, el establecimiento de un inventario general de propiedades, que necesariamente está signado por el momento de la elaboración del catastro (última década del siglo XIX). Lo que significa que pueden existir emplazamientos que no hayamos referenciado al haber perdido antes de esa fecha su nexo con el cdB. Se trata objetivamente de una primera limitación, derivada del uso de la documentación Terán, que repercute directamente sobre nuestro inventario de propiedades.

- En seguida, luego de haber establecido la lista de los extractos de protocolo para cada una de las propiedades repertoriadas (es lo que aparece en la segunda columna del cuadro anterior), hemos consultado los volúmenes respectivos y anotado los elementos de cada operación descrita: fundaciones e imposiciones, donaciones, ventas enfitéuticas, locaciones, permutas, redenciones de principales, etc. A partir de este momento, los errores cometidos en la elaboración del índice por Terán y colaboradores se han vuelto también los nuestros. De lo que ya pudimos darnos cuenta, al "encontrar al vuelo", revisando los volúmenes, ciertas referencias no repertoriadas por la Colección. Quedan seguramente muchas otras por corregir.

- La fase siguiente ha sido la reconstitución cronológica y lógica de las diferentes operaciones efectuadas sobre cada una de las propiedades. Se trataba en realidad de reconstruir su historia individual y de restituirle el encadenamiento sucesivo de cargas, obligaciones, transferencias y otras operaciones. Existen largos periodos de silencio, lo que atenta contra la inteligibilidad del proceso. Pero hay simultáneamente itinerarios de singular interés, en los que se también percibe, en filigrana, la evolución del comportamiento de la comunidad respecto a su patrimonio urbano. Ya lo explicitaremos en su momento.

\footnotetext{
${ }^{33}$ Grandi, El convento, 138.

${ }^{34}$ A.A.L, CNSB, X:6. Plan y Estado de las Fincas de este Convento de la Buenamuerte, 02/04/1834.
} 
Dado el carácter incompleto de la documentación, de la confusión que caracteriza el vocabulario y la prática notarial, pero también por causa del carácter aún introductorio de nuestra investigación, nos ha sido imposible por el momento intentar una cuantificación de la muestra constituida; lo que sería no obstante indispensable para completar el enfoque. Por el momento, no estamos en condiciones de responder, para el conjunto de la muestra, a interrogantes relacionadas con el área de los emplazamientos y a su relación con el área urbana total limeña, con la evolución global de los montos de los principales impuestos, con las sumas de dinero efectivamente pagadas (o su porcentaje) en las ventas enfitéuticas o con el ritmo de renovación de los contratos de locación y el aumento de los alquileres, ya en la segunda parte del siglo XIX.

Como lo sugerimos al comienzo de este artículo, nuestro interés se ha concentrado por el momento en la comprensión de los orígenes y del uso del patrimonio urbano de la comunidad, en los mecanismos de funcionamiento de las diversas cargas que pesan sobre él, en la red de relaciones que establecen los padres de la Buenamuerte con sus acreedores y deudores, en la evolución específica de su patrimonio, desde el punto de vista de la dispersión y la concentración de sus propiedades, enfin, en la forma cómo le afecta concretamente (y localmente) a dicho patrimonio, la legislación desvinculadora y desamortizadora del Estado peruano.

\section{c) Primeros resultados}

He aquí algunas de las observaciones más importantes.

- En primer lugar, desde el punto de vista del origen de las propiedades urbanas del cdB.

La variada mecánica de las donaciones a favor del cdB, que es uno de los mecanismos que le permitieron iniciar y acrecentar su patrimonio, se manifiesta también en la probable subevaluación de las propiedades que la comunidad compra (¿concertada o por piedad del vendedor? aún no lo sabemos a ciencia cierta) o, en su defecto, en la transferencia de propiedades que reconocen una fundación pía a favor de la comunidad o sus prelados ${ }^{35}$.

Por otro lado, según el procedimiento típico, y fuera de las operaciones enfitéuticas, cuando el cdB compra fincas y sitios urbanos, desde el primer momento de su implantación (primera mitad del siglo XVIII), incorpora al mismo tiempo la obligación de pagar los censos de los principales que "reconocen"dichas propiedades. Ocurre incluso que la propia compra sea la oportunidad para la creación, ante el notario mismo de la operación, de nuevas imposiciones

\footnotetext{
${ }^{35}$ Las referencias que presentaremos en esta parte del artículo sitúan, en primer lugar, con su nombre actual, la calle del emplazamiento considerado, siguiendo a continuación con el folio y el volumen de la Colección Terán de donde proviene la referencia, añadiendo entre paréntesis la fecha de la escritura notarial. Así, para este primer resultado, las referencias son las siguientes: Archivo General de la Nación (en lo sucesivo A.G.N.), Colección Terán (en lo sucesivo CT), Amazonas 6a, 242v J (29/12/1792), 57 T (28/07/1767), 525v A (27/10/1814); Ancash 9a, $57 \mathrm{~T}$ $(28 / 07 / 1767)$.
} 
sobre la propiedad. Así, una parte del precio por pagar se metamorfosea en principal impuesto sobre la finca, lo que le otorga al antiguo propietario (o a alguien a quien éste designe) el derecho de percibir una renta anual pagada por el cdB. A veces se trata también de imposiciones o fundaciones que deben producir réditos a favor de fiestas parroquiales o santorales precisos ${ }^{36}$.

El efecto neto de dichas operaciones es efectivamente un aumento de las cargas anuales del cdB (sus réditos), al mismo tiempo que un aumento del patrimonio propietal amortizado y una disminución del circulante que tendría que haber salido de las cajas del cdB para satisfacer el pago por el bien adquirido.

Concentración de propiedad en una institución eclesiástica aunque con sobrecargo de la renta anual por pagar, pero al mismo tiempo con intento de control (e incluso de aumento de control) sobre la masa monetaria en circulación: es probable que estemos delante de mecanismos de funcionamiento y regulación económicos de mediano plazo.

- Algunos padres e incluso prelados de la comunidad (como ocurre con otras instituciones) fueron nombrados albaceas de testamentos, en particular, durante la primera mitad del siglo XVIII ${ }^{37}$.

Se trata de una práctica relativamente extendida y que parece relacionarse tanto con la voluntad del testador de asegurar sus posibilidades de salvación eterna, como con la certeza de la pericia gestionaria de los eclesiásticos designados. Los prelados de la comunidad aprovecharon dicha nominación para crear rentas anuales a favor del cdB, cargadas a la masa de bienes recibida, o a veces para entrar directamente en posesión de determinadas fracciones de los legados, no siempre como poseedores colectivos ${ }^{38}$.

Por otro lado, algunos padres o prelados del $\mathrm{cdB}$, estén o no relacionados con la propiedad que sufre una determinada carga, se transforman en beneficiarios individuales de los réditos producidos por imposiciones o fundaciones efectuadas sobre dicha propiedad, luego de la muerte del beneficiario inicial o de su sucesor inmediato ${ }^{39}$. La escritura de creación puede incluso estipularlo así. Lo mismo ocurre con el patronato de capellanías de misas u otras fundaciones, que pasa a ser ejercido por dichos padres o prelados, con las ventajas que de ello se derivan ${ }^{40}$.

Estos hechos han provocado frecuentemente, en particular durante la segunda mitad del siglo $\mathrm{XIX}$, conflictos agudos, incluso judiciales, entre los antiguos prelados del cdB, que

\footnotetext{
36 A.G.N, CT, Amazonas 6a, 525v A (27/10/1814); Ancash 10a, 481 F (12/10/1822); Ancash 8a1, 453v F (27/03/1788); Caylloma 5a, 10v H (24/05/1841, 02/07/1841); Huanta 1aCouv2, 22 T (20/02/1747); Junín 4a, 134v F (14/01/1739), 288 C (04/11/1763), 163 G (01/08/1855); Paruro 1a3, 53 T (17/02/1764).

${ }^{37}$ A.G.N, CT, Arequipa 6a, 30v C (20/03/1767), 386 A (09/10/1781); Tacna 5a2, 112v M (03/10/1804).

${ }^{38}$ Ibídem. Lo que se opone a las reglas de la comunidad y a las leyes del imperio.

${ }^{39}$ A.G.N, CT, Ancash 11a, 193 H (06/10/1879); Huanta 1aCouv1, 65 F (31/10/1710).

${ }^{40}$ A.G.N, CT, Huanta 1aCouv1, 65 F (31/10/1710); Tacna 5a2, 269v M (09/05/1853); Ucayali 7a, 48v Q y 221v S (30/04/1748); Arequipa 6a, 386 A (09/10/1781), 416 A (04/10/1783), 11 R (08/08/1783).
} 
reivindicaban un usufructo individual, y las nuevas autoridades de la comunidad, que lo reclamaban para ella en su conjunto ${ }^{41}$. Indiscutiblemente, el individualismo avanza por el terreno fértil del declive general de ingresos, rentas y pensiones del cdB.

- Aun cuando no dispongamos por el momento de los elementos que nos permitirían cuantificarlo, es necesario precisar que durante las supresiones del cdB, en particular durante la primera, las autoridades gubernamentales adoptaron diferentes medidas, en perjuicio del patrimonio y las rentas de la comunidad.

A la percepción estatal de alquileres y cánones enfitéuticos (de que normalmente gozaba la comunidad crucífera), transferida a favor de las tesorerías departamentales o de la Dirección de Consolidación, a veces con la decisión unilateral de disminuir el monto de las sumas pagadas ${ }^{42}$, se puede agregar el establecimiento de contratos de venta enfitéutica, firmados ante notario, en los que la institución gubernamental aparece ya como poseedora efectiva de la propiedad objeto del contrato $^{43}$. En otros momentos es la cesión directa, pura y simple, de rentas y censos percibidos por el cdB a favor de particulares o la transmisión de derechos de capellanías u otras imposiciones al Estado, o a favor de entidades paraestatales, cuando no de particulares ${ }^{44}$.

Es posible pensar que tales operaciones, ejecutadas por la autoridad pública, lograran desbaratar parcialmente cierta estrategia de preservación de propiedades desplegada por la comunidad, con la ayuda de allegados y benefactores particulares ${ }^{45}$. Pero es igualmente interesante constatar, incluso si se tratara de un caso aislado, cómo el Estado republicano, presuntamente liberal y "progresista", mantiene y no modifica la técnica de usufructo y venta de propiedades que al menos temporalmente acaba de "nacionalizar".

Algunas de estas propiedades, más raramente en el caso de los principales y réditos dispuestos, revirtieron al cdB luego de sus dos restablecimientos, a veces sobrecargadas con nuevas obligaciones y rentas anuales por pagar. Otras fueron objeto de demanda judicial por parte del $\mathrm{cdB}^{46}$.

En todo este proceso, más que de desamortización, es posible hablar de expropiación irregular y de transferencia de usufructo por decisión de la autoridad pública, no observándose una voluntad determinada de liquidar ni el "régimen de propiedad" vigente, ni su lógica de

\footnotetext{
${ }^{41}$ A.G.N, CT, Tacna 5a2, 269v M (09/05/1853).

${ }^{42}$ A.G.N, CT, Ancash 8a1, 80v N (04/06/1828), 111v D (12/10/1841), 593v A (06/09/1847).

43 A.G.N, CT, Ancash 8a1, 111v D (12/10/1841), 593v A (06/09/1847); Junín 4a, 345 T (16/05/1848), $70 \mathrm{~S}$ $(16 / 01 / 1856)$

${ }^{44}$ A.G.N, CT, Atahualpa (la "casa" Santa Liberata, en el barrio de Abajo del Puente), 10 N (15/10/1835), 375v I (28/03/1877); Tacna 5a2 (cesión de propiedad a la Universidad de San Marcos), 247v H (22/03/1887).

${ }^{45}$ A.G.N, CT, Ancash 8a1, 111v D (12/10/1841), 593v A (06/09/1847).

${ }^{46}$ A.G.N, CT, Andahuaylas 2a, 24v V2 (07/06/1893), 80v V2 (22/01/1902).
} 
funcionamiento ${ }^{47}$. Es probable que dicha caracterización pueda ser aplicada, a mediano plazo, a la actitud del Estado peruano frente a la problemática del "antiguo régimen" propietal, particularmente ante la propiedad eclesiástica ${ }^{48}$, fuera de las coyunturas de ofensiva liberal. Lo que por otro lado, y desde el punto de vista de la metodología de investigación, replantea la exigencia de contrastar permanentemente el discurso de las élites y los textos legales con su aplicación precisa.

- La extensión de la locación como práctica de valorización de la propiedad urbana, muy a menudo (aunque no definitivamente) a expensas de la venta enfitéutica, parece confirmarse desde fines de los años 60 del siglo XIX, probablemente ligada al dinamismo simultáneo de la demanda urbana, medido por el número importante de cesiones y transferencias, y atestigüado por las operaciones que efectúa el cdB.

Conviene resaltar al respecto la confusión en el vocabulario notarial empleado, en el que "arrendamiento" no siempre corresponde a una locación "moderna" sino que puede simple y llanamente referirse al uso del dominio útil de la enfiteusis. Puede que no sólo sea una confusión semántica, sino que refleje la propia dificultad generada por el paso vacilante de una práctica hacia la otra. También puede tratarse de un fenómeno generado por la intervención del notario, agente intermediario y conocedor de la ley, para favorecer determinado tipo de contratos y propietarios. Es evidente, sin embargo, que se asiste, a lo largo de los años 70, a una acentuación de la tendencia a renovar los contratos antes de su expiración efectiva, con modificación de los alquileres pactados ${ }^{49}$. Lo que puede poner de manifiesto, al mismo tiempo, la respuesta de las partes contractulales al movimiento del mercado y la voluntad de los propietarios de mejorar el rendimiento financiero de la propiedad inmueble urbana.

Por otro lado, durante los años 80 (y ya desde fines de los 70) se observa la firma de contratos de locación con alquileres progresivos, que se reajustan automáticamente cada 3 o 4 años, aplicados tanto a lugares de habitación como a tiendas y pulperías ${ }^{50}$. Se perciben igualmente en dichos contratos el tránsito monetario decretado por el Estado y los desastres financieros, de los que la guerra del Pacífico es el telón de fondo. Luego del paso del peso al sol, que se generaliza durante los años 70 , se puede registrar el tránsito de los soles billetes, que serán finalmente repudiados, a los soles de plata metálica, valor de refugio en un periodo de inflación acelerada.

\footnotetext{
${ }^{47}$ Es a veces toda la coherencia económica de la supresión de conventos y monasterios, efectuada por la autoridad pública, la que aparece imperceptible. Las indicaciones sobre el "estado de abandono" de los conventos supresos son numerosas. A.A.L., CNSB, (1830),IX:89.

${ }^{48}$ Se puede hablar incluso de operaciones en las que el propio estado republicano "reamortiza" propiedades a favor de ciertos conventos (o sus capellanes designados). Por ejemplo, el 07/08/1832, cuando efectúa una operación de dicha naturaleza con principales que habían pertenecido al Tribunal de la Inquisición, a favor del capellán del convento supreso de Santo Domingo de Chincha Baja (Ica). A.A.L., CNSB, (15/06/1855), XII:3.

${ }^{49}$ A.G.N, CT, Huanta 1aCouv1 (operaciones efectuadas son las instalaciones mismas del convento), $353 \mathrm{v} \mathrm{M}$ (15/06/1859), 372 M (21/10/1862), 331v S (03/07/1873), 415v G (03/02/1879), 433v J (24/08/1886), $445 \mathrm{~J}$ (21/06/1888), 101 N (04/10/1842); Ancash 7a, 480v L (30/05/1871), 378 I (04/12/1877), 198v N (18/09/1885), 235v Ñ (27/03/1897); Moquegua 4a, 89 E (17/04/1869), 162 E (27/06/1874), $231 \mathrm{~W}(12 / 08 / 1890)$.

50 A.G.N, CT, Ancash 8a1, 276 H (09/07/1889), 664 L (07/06/1890); Ancash 8a2, 112 E (08/10/1870), 443 M $(02 / 08 / 1877), 199 \mathrm{v}$ N2 (06/11/1885).
} 
Se puede incluso observar la firma de contratos en libras sterling, desde 1880, así como transacciones desafortunadas que, antes de 1888 , conducen a la expropiación y transferencia patrimoniales, particularmente cuando, a la víspera de la desvalorización del billete bancario transformado en fiscal, se producen operaciones de venta inmobiliaria ${ }^{51}$, pagadas en billetes. En lo que fue un ejemplo del carácter "subversivo" y expropiatorio de los fenómenos de debacle y quiebra monetarias.

- Durante este periodo, el cdB parece utilizar alternativa y pragmáticamente tanto la venta enfitéutica como el alquiler ${ }^{52}$.

Así, podríamos afirmar que en ciertas ocasiones, el cdB aparece como un agente "moderno", tal vez favorable a la unificación de los dos dominios de la propiedad, el útil y el directo, herencia del antiguo régimen, y su tránsito (más o menos acelerado) hacia la práctica del arrendamiento, con redefinición periódica del monto del alquiler impuesto. Esta negociación y renegociación de alquileres es, desde luego, un factor importantísimo en los momentos de inflación a los que nos hemos referido anteriormente.

Pero fuera del fenómeno inflacionario y monetario, el cdB parece más bien adaptarse, en su comportamiento práctico, a unas condiciones inmobiliarias en las que, por diversas razones, aumenta la demanda urbana, tal como lo hemos indicado anteriormente.

En otros momentos, hay que decirlo, el fenómeno no se produce y el cdB parece optar, a veces apelando a pleitos y procesos judiciales, por las formas antiguas de posesión, usufructo y transferencia. Tanto en uno como en otro caso, las operaciones efectuadas parecen tomar muy a la ligera la legislación vigente y los derechos de arrendatarios y enfiteutas.

Podríamos decir entonces que la comunidad de la Buenamuerte se nos presenta, en particular en la segunda mitad del XIX, en pleno aprendizaje de pragmatismo, ante la penetración de la "modernidad", delante de sus necesidades y frente a las posibilidades del mercado. Es probable que lo mismo ocurra con el resto de las órdenes religiosas y sus propiedades, lo que sería ya una indicación importante. Pero este fenómeno requiere un estudio cuantitativo más profundo.

Otro elemento que conviene poner de relieve en la práctica específica del $\mathrm{cdB}$, se relaciona con las modalidades del arrendamiento y sus beneficiarios. La locación de determinadas propiedades de la comunidad, así como la fijación del alquiler, aparecen frecuentemente ligadas a operaciones de crédito (préstamos a favor del $\mathrm{cdB}$ ) efectuadas anteriormente con los

\footnotetext{
${ }^{51}$ A.G.N, CT, Huanta 2a, 372v J (22/06/1880), 377 J (24/11/1880), 402v J (12/04/1881), 82v W (23/05/1882), 436v J (26/11/1886); Paruro 1a3, 648 L (22/09/1887); Paruro 1a4, 655 L (16/11/1888). Sobre el repudio del billete fiscal ver Pablo F. Luna, "1888: el rechazo definitivo del billete fiscal”, en La urgencia del cambio (Lima: CIUP, 1988): 115122.

${ }^{52}$ A.G.N, CT, Huanta 1aCouv1, 415v G (03/02/1879), 433v J (24/08/1886), 445 J (21/06/1888); Huanta 1aCouv2, 199 N2 (26/09/1885), 285v N (22/06/1898); Huanta 2a (el callejón Quintana), 376 G (06/04/1877), 189v H (10/06/1879), 446v S (03/05/1880), 372v J (22/06/1880), 377 J (24/11/1880), 402v J (12/04/1881), 436v J $(26 / 11 / 1886)$
} 
beneficiarios del contrato. En algunas oportunidades ocurre incluso que los alquileres practicados compensen los intereses que se derivan de tales operaciones de crédito. Otras veces se trata, y no es menos interesante, de compensar, de manera total o parcial, los réditos de imposiciones que el cdB ha dejado de pagar desde hace mucho tiempo. Se trata de "compensaciones" que se producen a lo largo del siglo XIX, por deudas que fueron contraídas en décadas anteriores ${ }^{53}$.

Conviene resaltar tambien que, aún a fines del siglo XIX y comienzos del XX, el cdB continúa pagando réditos anuales procedentes de capellanías laicales "reconocidas" por sus propiedades situadas en el entorno del convento ${ }^{54}$.

- Durante esta revisión de la evolución del patrimonio urbano del $\mathrm{cdB}$, hemos podido detectar la existencia de ciertas propiedades que, poseídas o no por la comunidad, presentan un itinerario peculiar, durante el siglo XIX.

Luego de haber formado parte, durante el siglo XVIII, de alguna masa de bienes, de herencias o testamenterías, y de haberse desprendido de ellas, por diversas razones (conflictos de familia, liquidación por insolvencia, etc.), la unidad propietal individualizada experimenta a su vez, ya en el siglo XIX, un fraccionamiento en su existencia, generado ya sea por venta, por división o pleito entre los miembros del grupo familiar que la recibió, o por pago de deudas. Antes de asistir a una nueva reconcentración, hacia fines de siglo, promovida por un nuevo propietario, que puede o no ser allegado de la familia poseedora anteriormente ${ }^{55}$.

Aunque el calendario no sea el mismo para cada una de las propiedades en las que hemos detectado tal itinerario, lo específico es que este tránsito significa también el paso de la posesión familiar colectiva de la unidad propietal a una propiedad individual (personal), para la que el nuevo propietario ha procedido también a su "perfeccionamiento" y homogeneización. Es decir, a la redención en la Dirección de Crédito Público de las cargas y servidumbres que pesaban sobre ella, según las condiciones establecidas por la ley, y a la concreta "unificación de dominios", abriendo paso a la propiedad "total y absoluta" del nuevo propietario, independientemente del uso que éste le destine a dicha propiedad. Se trata de un itinerario "ejemplar" que, por el momento, estamos incapacitados de calificar de "típico".

- Finalmente, y aunque no se desprenda directamente de los datos de la Colección Terán, podríamos indicar que un buen número de contratos notariales por ventas enfitéuticas o alquiler de casas consignan, ya al promediar el siglo, varias cláusulas que exigen

\footnotetext{
${ }^{53}$ A.G.N, CT, Ancash 9a, 199 N2 (09/10/1885); Arica 7a, 21v Ñ (24/08/1887); Paruro 1a6, 319 I (10/11/1875), 649 L (27/10/1887), 434v I (24/07/1879), 469v J (03/10/1890), 592v I (05/05/1891).

${ }_{54}$ A.G.N, CT, Ancash 8a1, 12v W2 (13/07/1901), 47v W2 (12/02/1903); Huanta 1a2, 158v Ñ (02/08/1894).

${ }^{55}$ A.G.N, CT, Arequipa 6a, 118 I (07/10/1850), 119 I (27/07/1852), 564 L (04/09/1877), 168v N (06/09/1890), 174 N (29/09/1891), 176 N (17/08/1891), 37v V2 (13/11/1895); Junín 4a, 345 T (16/05/1848), 163 G (01/08/1855), 70 S (16/01/1856), 183v W (25/09/1888), 7v W2 (15/05/1901), 17 W2 (03/10/1901).
} 
reparaciones en la fábrica de las fincas objeto de contrato, que el enfiteuta o el locatario deben efectuar.

A veces se trata de la reconstrucción total de partes de la finca, de su entrada o su entorno o instalaciones inmediatos. Dichas mejoras, dicen los contratos, quedarán incorporadas al patrimonio del cdB, luego de la expiración de los plazos previstos ${ }^{56}$, sin que se estipulen indemnizaciones formales ${ }^{57}$.

Se trata entonces, en primer lugar, de un crecimiento del valor patrimonial del convento en su puesta en usufructo, financiado por el enfiteuta o el locatario, $y$, en segundo lugar, de un modo de mantenimiento de las fincas urbanas que precede a la intervención municipal, que sólo se generalizará a fines de siglo, o a la de las compañías urbanizadoras, que sólo entrarán verdaderamente a tallar después de la guerra del Pacífico. Es probable también que ambos procesos correspondan a la evolución del comportamiento de otras órdenes religiosas, en el momento de valorizar su patrimonio.

\section{Nota final}

$\mathrm{Al}$ acercarnos, desde un observatorio local, a las problemáticas globales de desvinculación y desamortización en Perú, y de transformación de la propiedad urbana limeña, durante el siglo XIX, hemos obtenido algunos resultados que son, desde ya, nuevas interrogantes para trabajos ulteriores. Sobre el papel regulador desempeñado por la institución religiosa católica en la vida económica urbana (¿solamente?) que se prolonga ostensiblemente más allá de las primeras décadas de la república. Con respecto a la estrategia desplegada por las órdenes religiosas, para asegurarse fuentes de rentas a mediano plazo, y el conflicto entre la posesión y el usufructuo individuales y comunitarios, que el progreso de la secularización agudizará paulatinamente.

Pero asimismo, esta primera aproximación nos ha permitido observar que, por ejemplo, el cdB ha desarrollado una estrategia muy concreta, adaptada a su entorno de implantación. Tanto al asegurarse la posesión de callejones y similares lugares de vivienda popular, como también integrando sus propias necesidades materiales al universo local de trabajo y subsistencia ${ }^{58}$. Con lo que la propagación de la fe y el desempeño de su misión han podido materializarse, desde el punto de vista sociológico.

Nuestro trabajo nos ha permitido también percibir a grandes trazos la vacilación casi estructural y la incoherencia del Estado republicano y el personal político decimonónico, confrontados a

\footnotetext{
${ }^{56}$ A.A.L., CNSB, XII:3. Razón circustanciada de las rentas del Convento de la Buenamuerte, modo en que se recaudan, inversión de fondos y obligación de misas, con datos de fundación, razón de religiosos y constitución de seglares. Lima, 15/06/1855.

${ }^{57}$ Lo que no impide que pueda haber compensaciones "no escritas", con lo que ingresamos al terreno de las deudas informales.

${ }^{58}$ Esta vocación de integración es igualmente compartida por los monasterios femeninos limeños. Nuestros trabajos recientes, aún inéditos, sobre las clarisas limeñas confirman esta tendencia que hace que parientes y allegadas de las monjas y madres del monasterio beneficien de un empleo u ocupación temporal.
} 
una presunta tarea de "liberar" la propiedad y "perfeccionarla". Actitudes dubitativas y cambiantes, comparadas con el pragmatismo con el que, en el otro campo, las órdenes y la Iglesia Católica parecen haber enfrentado la lenta penetración de la "modernidad", tanto en lo que se refiere a oportunidades para consolidar su fuerza patrimonial, aunque sea a expensas de enfiteutas y locatarios, como en lo que se relaciona con la erosión efectiva de su influencia moral y material, la que trataban de limitar y contrarrestar.

Así, el cdB, nuestro observatorio local, ha sido víctima (y beneficiario) de este vaivén legislativo y de las coyunturas de tensión entre el Estado y la Iglesia Católica, en particular durante las primeras décadas de la vida independiente. Pero se requiere aún cuantificar con mayor detalle los efectos de las medidas que le afectaron, para explicar si su estrategia de preservación de rentas y propiedades es sobre todo esfuerzo de sobrevivencia o más bien reflejo de "modernidad". Sabiendo desde ahora que, en este mismo campo de la propiedad urbana, hay otras instituciones limeñas para las que el siglo XIX no fue un periodo de tragedia ni de expoliación. El pragmatismo de la órdenes y la defensa más o menos meticulosa de sus intereses materiales dejan poco sitio a especulaciones sobre alguna autoimpuesta misión "histórica" de perfeccionamiento de la propiedad.

Y sin embargo, volviendo al tema de la transición en el régimen de propiedad, cuando consideramos algunos itinerarios propietales específicos, sorprenden a veces la limpidez y la eficacia con las que la legislación republicana, al ser puntualmente aplicada, parece completar la evolución tendiente a "desesclavizar" y "perfeccionar" definitivamente la división o el desdoblamiento de dominios de dichas propiedades, con el fin probable de facilitar su circulación. Lo que replantea una vez más, desde el terreno de su aplicación concreta, el problema de la naturaleza social y la presunta generalidad de la legislación peruana del siglo XIX. Pero estamos indiscutiblemente ante unos procesos cuya complejidad excluye cualquier conclusión apresurada. 


\section{Bibliografía}

Acevedo y Criado, Ismael. La institución del Registro de la propiedad inmueble en el Perú, sus antecedentes legales y formas más urgentes. Lima: UNMSM, 1959.

Archivo Arzobispal de Lima. Guía del Archivo Arzobispal de Lima, 1543-1899. Historia, fondos documentales y reglamento, elaborado por L. Gutiérrez A., J. C. García C., y L. Gómez A. Lima: Arzobispado de Lima, 1995.

Catálogos. Laura Gutiérrez A., coord. Madrid: Arzobispado de Lima, Fundación Tavera, AECI, 1999.

Archivo General de la Nación. Guía del Archivo Histórico. Lima: AGN, 1997.

Basadre, Jorge. Historia de la República del Perú. Lima: Ed. Universitaria, 1968-1969.

Bromley, Juan y José Barbagelata. Evolución urbana de la ciudad de Lima. Lima: Tall. Gráf. Ed. Lumen, 1945.

Cisneros, Carlos B. "Monografía del Departamento de Lima". Boletín de la Sociedad Geográfica de Lima, (1911) 26:121-181.

Córdova y Urrutia, José María. Estadística histórica, geográfica, industrial y comercial de los pueblos que componen las provincias del Departamento de Lima, 2 vols. Lima: Imprenta de Instrucción Primaria, 1839.

Fuentes, Manuel Atanasio. Guía del viajero en Lima. Guía histórico-descriptiva, administrativa, judicial y de domicilio de Lim., Lima: Librería Central, 1860.

García Calderón, Francisco. Diccionario de la legislación peruana, 2 vols. Lima, Paris: Librairie de Laroque Jeune, 1879.

García Jordán, Pilar. "Estado moderno, Iglesia y secularización en el Perú contemporáreo (1821-1919)" Revista Andina, no 2, (1988): 351-401.

Iglesia y poder en el Perú contemporáreo, 1821-1919. Cusco: Centro Bartolomé de Las Casas, s.d. (1991?).

Gento Sanz, Benjamín, OFM. San Francisco de Lima; estudio histórico y artístico de San Francisco. Lima: Imp. Torres Aguirre, 1945.

Gerhards, Agnès. Dictionnaire historique des ordres religieux. París: Fayard, 1998.

Goutier, Charles. "L'ordre de Saint-Camille", en Enciclopedia Universal Espasa Calpe. París, 1926.

Grandi, Virgilio M.I. El convento de la Buenamuerte. 275 años de presencia de los padres camilos en Lima. Bogotá: Lit. Guzmán Cortés, 1985.

Larreátegui Hinffen, Víctor D. La prescripción censítica como doctrina legal. Lima: UNMSM Facultad de Jurisprudencia, Imp. La Industria, 1902.

Levaggi, Alberto. Las capellanías en la Argentina, estudio histórico-jurídico. Buenos Aires: UBA, 1992.

"El proceso desamortizador y desvinculador de los bienes de manos muertas desde la óptica jurídica" Cuadernos de Historia Latinoamericana, no. 7 (1999): 33-60.

Luna, Pablo F. "1888: el rechazo definitivo del billete fiscal" en La urgencia del cambio. Lima: CIUP, 1988. 
Macera, Pablo. "Iglesia y economía en el Perú durante el siglo XVIII", en Trabajos de Historia. Lima: INC, 1977.

Martínez de Codes, Rosa María. "El proceso desvinculador y desamortizador de bienes eclesiásticos y comunales en la América Española, siglos XVIII y XIX". Cuadernos de Historia Latinoamericana, no. 7 (1999): 7-31.

Miró Quesada, Aurelio. "Lima en 1839". Boletín de la Sociedad Geográfica de Lima 82, (1964): 53-59.

Panfichi, Aldo. "Urbanización temprana en Lima 1535-1900", en Aldo Panfichi H. y Felipe Portocarrero S. Mundos interiores: Lima 1850-1950. Lima: CIUP, 1995: 16-42.

Piel, Jean. Capitalisme agraire au Pérou, 2 vols. Paris: Ed. Anthropos, 1975-1983.

"Las leyes de desamortización y su importancia en el proceso neolatifundista republicano en el Perú, de 1824 a 1924”, en Actas del XI Congreso Internacional de AHILA. Liverpool: 1996, 3:257-272.

Poulet, Ch. Histoire de l'Eglise. París: Ed. Beauchesne et ses fils, 1953.

Ramón J., Gabriel. "Con la patria en las paredes: la regularización de la nomenclatura urbana de Lima (1861)". Contracorriente, no. 1 (1997): 85-104.

Redescubramos Lima: Iglesia de San Pedro. Lima: Fondo Pro-recuperación del Patrimonio Cultural de la Nación, 1996.

Tineo M., Melecio. El Archivo histórico arzobispal de Lima y sus fondos documentales. Lima: UNMSM, 1992.

Von Wobeser, Gisela. "Mecanismos crediticios en la Nueva España. El uso del censo consignativo", Estudios Mexicanos 5, no. 1, (1989): 1-23.

"La fundación de capellanías de misas, una costumbre arraigada entre las familias novohispanas. Siglos XVI-XVIII", Jahrbuch für Geschichte Lateinamerikas, no. 35 (1998): 25-44. 